\title{
Sarcomatoid Chromophobe Renal Cell Carcinoma with Heterologous Component
}

\author{
Sushma Bharti ${ }^{1}$, Gautam Ram Choudhary ${ }^{2}$, Naresh Jyotsna Bharti ${ }^{*}$ \\ Garg Pawan Kumar ${ }^{3}$, Poonam Abhay Elhence ${ }^{1}$, Arsha BS ${ }^{4}$ \\ Department of Pathology, AIIMS, Jodhpur, Ministry of Health and Family Welfare, Basni, India \\ Department of Urology, AIIMS, Jodhpur, Ministry of Health and Family Welfare, Basni, India \\ Department of Diagnostic and interventional Radiology, AIIMS, Jodhpur, Ministry of Health and Family Welfare, Basni, India \\ Department of Pathology, AIIMS Jodhpur, India
}

Scan to discover online

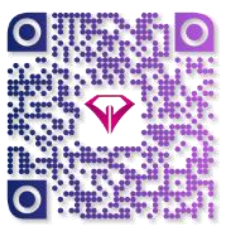

\begin{tabular}{c}
\hline Main Subjects: \\
Uropathology \\
\hline
\end{tabular}

Received 10 June 2019;

Accepted 28 Nov 2019;

Published Online 26 Dec 2019;

10.30699/IJP.2019.109242.2147

PMCID: PMC6995683

PMID: $\quad \underline{32095153}$

\begin{abstract}
Clear cell renal cell carcinoma (RCC) is the most common malignant renal tumor in adults, while chromophobe RCC (CRCC) is the third most common. Any subtypes of $\mathrm{RCC}$ can undergo sarcomatoid differentiation, but heterologous differentiation in sarcomatoid area is very rare in RCC. Here a 61-year male is presented with hematuria and palpable mass. Clinicoradiologically, RCC was considered and left radical nephrectomy was performed. A well-circumscribed renal mass located in the upper pole of the left kidney with variegation and extensive areas of bony hard calcification noted, was reported as CRCC with sarcomatoid differentiation containing heterologous component. CRCC subtype has good prognosis but show dismal prognosis when associated with sarcomatous differentiation. We found 11 cases of sarcomatoid CRCC containing heterologous elements reported in indexed English literature. CRCC must be differentiated from Conventional RCC and Oncocytoma. The extensive sampling of the tumor is needed. We report a very rare case of CRCC with sarcomatoid differentiation containing heterologous elements.
\end{abstract}

KEYWORDS: Chromophobe, Renal cell carcinoma, Sarcomatoid, Kidney neoplasms, Cell differentiation

Corresponding Information: Jyotsna Bharti Naresh, MD, Department of Pathology, AIIMS, Jodhpur, Ministry of Health and Family Welfare, Basni, India Email:jyotsnamamc@gmail.com

Copyright $(\odot)$ 2020. This is an open-access article distributed under the terms of the Creative Commons Attribution- 4.0 International License which permits Share, copy and redistribution of the material in any medium or format or adapt, remix, transform, and build upon the material for any purpose, even commercially

\section{Introduction}

Recently Renal cell cancer (RCC) is the commonest renal tumor in adults, while it accounts for approximately $3 \%$ of all adult malignancies, and is the 12 th most common cancer in the world. Classifying RCC based on combination of morphology, molecular and genetic features, clear cell RCC is the commonest (70-90\%), which follows by papillary RCC (10-15\%) and then chromophobe RCC (CRCC) (3-5\%) (1). CRCC accounts for approximately 5\%of surgically removed renal epithelial tumors. Common presentation of RCC is triad of pain, flank mass and hematuria. Sarcomatoid differentiation that can be seen in any subtypes of RCC and CRCC is the third most common subtype associated with sarcomatoid differentiation (2). CRCC subtype has good prognosis but shows dismal prognosis when associated with sarcomatous differentiation (3). Herein, we report a rare case of CRCC with sarcomatoid differentiation containing heterologous component.

\section{Case Report}

A 61-year old male referred to the urology clinic with a palpable mass in the lower left abdomen and hematuria.
A contrast-enhanced CT scan revealed a heterogeneous peripherally enhanced tumor with a central hypovascular area (Figures 1 and 2); clinicoradiologically RCC was suspected and left radical nephrectomy was performed. Grossly, a well-circumscribed solid, beige tumor measuring $7 \times 6 \times 7 \mathrm{~cm}$, located in the upper pole of the left kidney with variegated areas where extensive bony hard calcification were noted (Figure 3). Sections showed a biphasic tumor, having epithelial tumor cells arranged in lobules, sheets and vague nodular pattern separated by fibrovascular septa, which were histomorphologically in favor of CRCC. Large proportion of sarcomatoid areas, dystrophic calcification and lacy malignant osteoid intermingled with malignant spindle cells (osteosarcoma component) were also noted. Large areas of hemorrhage and coagulative necrosis were present (Figure 4). Epithelial tumor cells were immunoreactive for CK7 and E-cadherin and immunonegative for CD10 and Vimentin (Figure 5). The sarcomatoid areas were immunopositive for Vimentin. There were perinephral tumor deposits, lymph node metastasis and perineural invasion. The final diagnosis was given as CRCC with sarcomatous differentiation containing osteosarcoma component. 


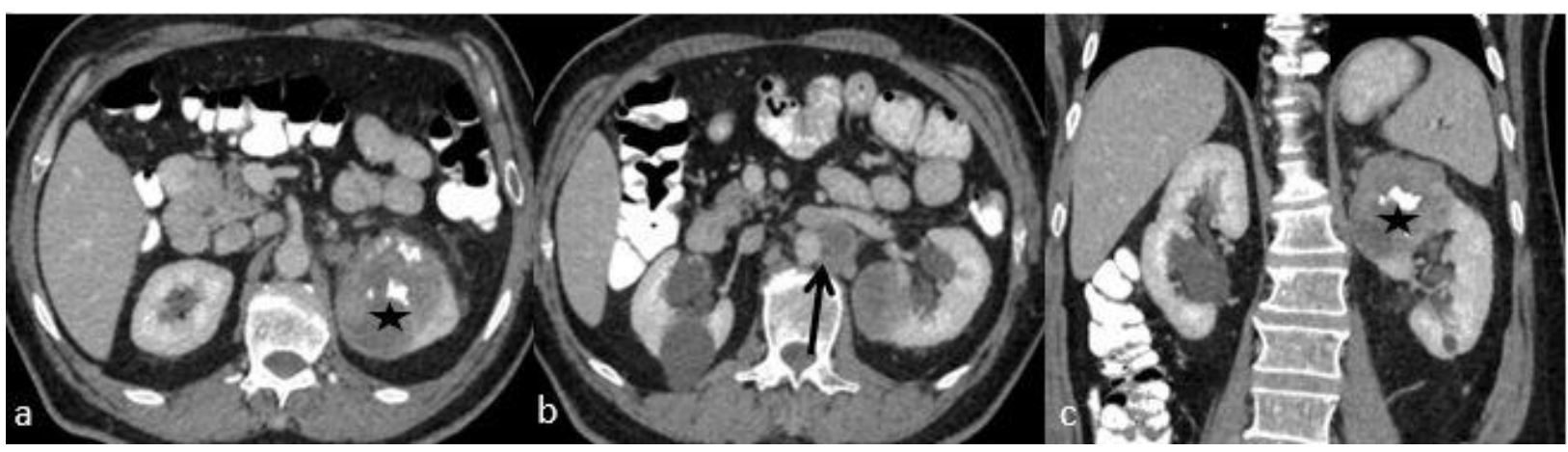

Fig. 1. CECT abdomen, axial (a, b) and coronal (c) images showing heterogeneously enhancing mass (asterix) at upper pole of left kidney with calcification and necrosis. Enlarged lymph nodes in left para-aortic area (black arrow).

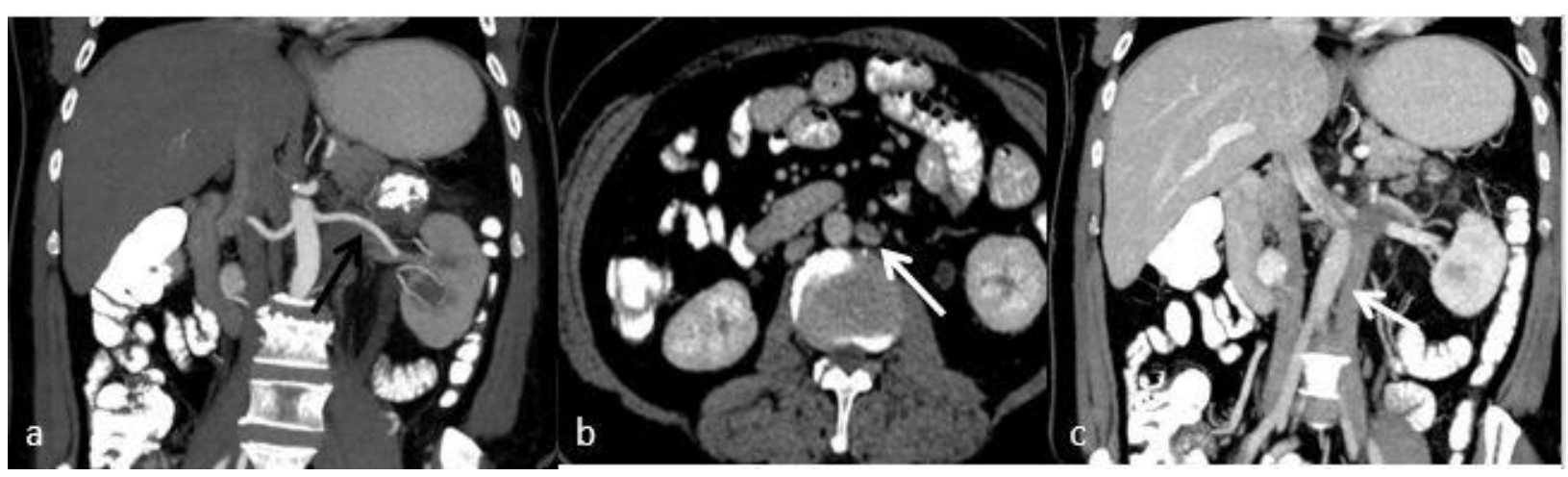

Fig. 2. CECT abdomen (a) showing single left renal artery (black arrow) and (b, c) images showing duplication of IVC on both side of aorta. Left renal vein draining into left side IVC (white arrow).

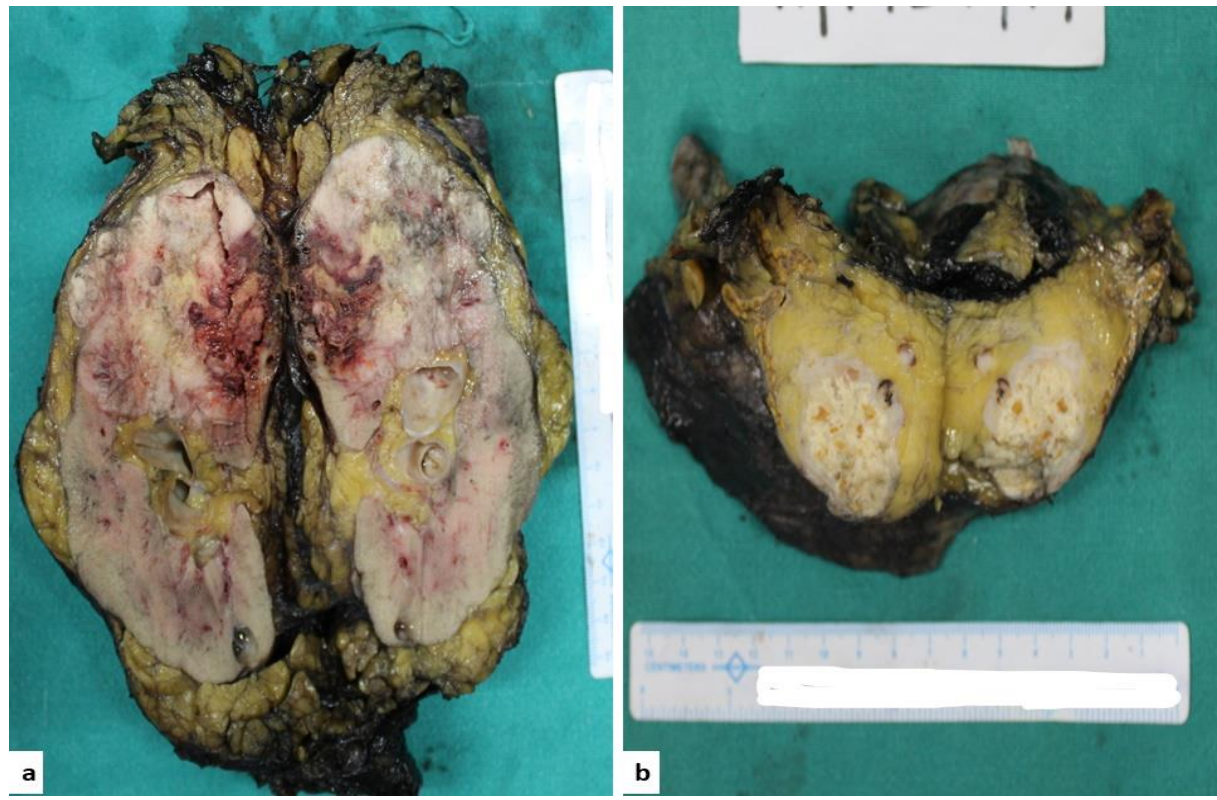

Fig. 3. Upper pole of kidney shows grey white to grey brown mass (a) perinephral fat shows tumor deposits (b). 

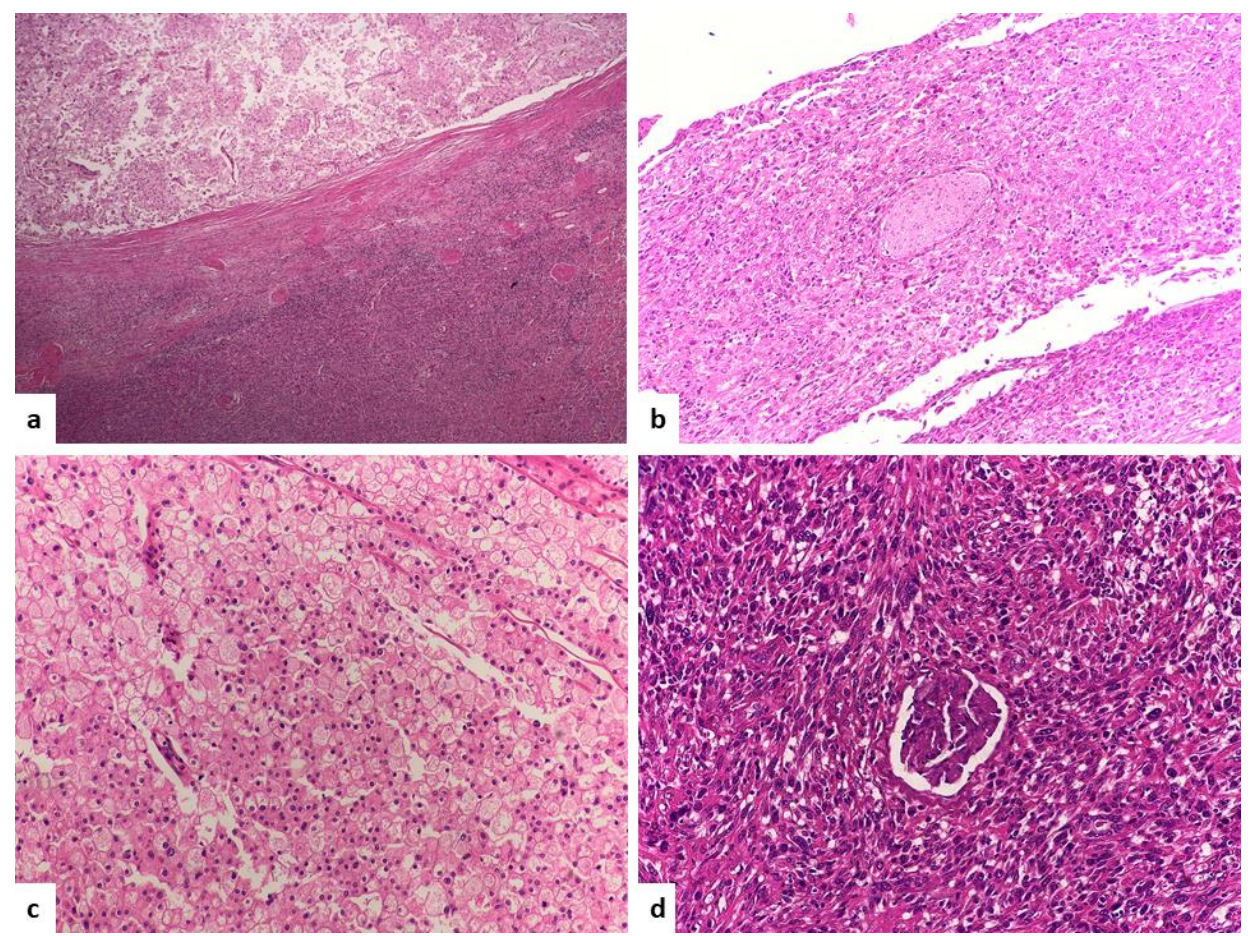

Fig. 4. Epithelial and spindle-shaped tumor cells (H\&E, 10x a) perineural invasion (H\&E, 20x b) epithelial tumor cells with centrally placed nuclei and perinuclear halo (HE 40x c), entrapped glomeruli in sarcomatoid tumor cells (H\&E, 40x d).
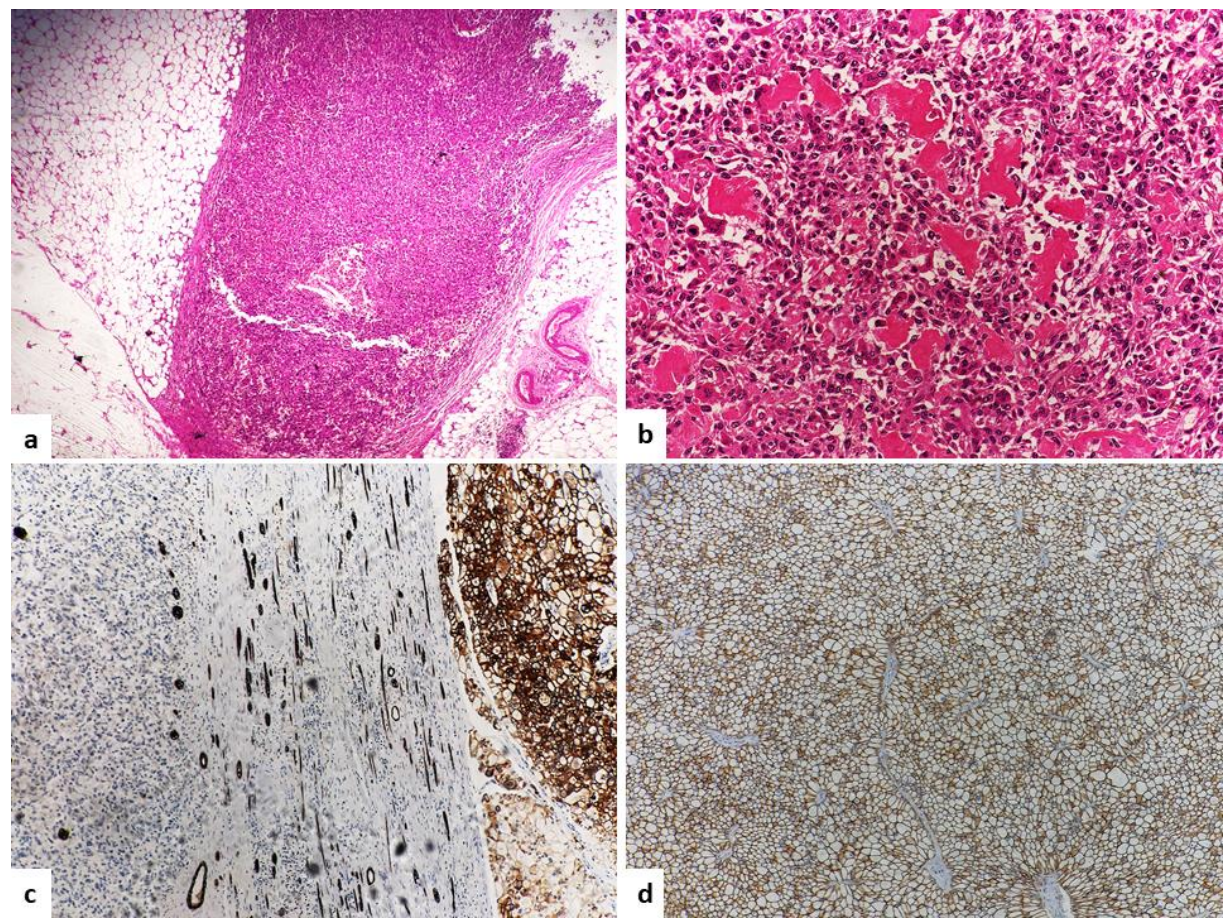

Fig. 5. Tumor deposits in perinephric fat (H\&E, 10x a) osteosarcoma component (H\&E, 40x) b) CK 7 immunoreactivity in epithelial tumor cells and unremarkable tubules of normal kidney, spindle cells are negative (H\&E, 10x c). E- Cadherin immunoreactivity in epithelial tumor cells (H\&E, 20x d).

\section{Discussion}

Tryouts CRCC was first described by Thoenes et al. in 1985 (4). It is a distinct subtype of RCC having good prognosis than the classical clear cell RCC (5). CRCC arises from the intercalated cells of cortical segment of the collecting system. Therefore, these tumors have distinct morphological, histochemical and ultrastructural features along with unique molecular, genetic and clinical characteristics. Steffens S. et al. concluded that unlike conventional RCC, Fuhrman nuclear grading system for RCC is not applicable for prognosis in case of CRCC, as it showed inherent nuclear pleomorphism; therefore it was considered an inappropriate grading system for CRCC (6). Paner et 
al. gave a novel grading system based on nuclear crowding and anaplasia for CRCC (7). The grading system for nonsarcomatoid CRCC was an independent predictor of tumor recurrence, metastasis, or death and it was a stronger predictor of adverse outcome than of tumor size and pathological (pT) stage. However, Fuhrman grading system was not found to be an independent predictor of outcome. Cheville JC et al. concluded that Tumor (T), Nodes (N), Metastasis (M) stage groupings and sarcomatoid differentiation are significantly associated with cancer specific survival in CRCC (2). CRCC is a highly aggressive neoplasm with increased risk of metastasis when associated with sarcomatoid differentiation, necrosis or angiolymphatic invasion (3). Mean age of incidence is in the sixth decade with almost equal sex predilection. Major cause of CRCC is tobacco smoking. Classical traid of pain, flank mass and hematuria are not seen in nearly $40 \%$ of cases. CRCC is further subdivided histologically into two variants, classical (conventional) and eosinophilic (oncocytic) type. Histologically, conventional type consists of round to polygonal cells with a perinuclear clear halo, pale or eosinophilic cytoplasm and distinct cytoplasmic borders having irregular wrinkled hyperchromatic nuclei with irregular nuclear membrane and small nucleoli. Sometime binucleation, low mitotic activity except in the sarcomatoid areas are noted. In eosinophilic variant, the cells have an oncocytic cytoplasmic appearance with less apparent nuclear features. The tumor cells show diffuse cytoplasmic staining with Hale's colloidal iron stain. Immunohistochemically, the tumor cells are immunoreactive with CD117, CK7, CK14, and EMA and negatively with HMWCK, CK20, vimentin and CD10. Unlikely, conventional RCC's which are immunonegative for CK7 and immunopositive with CD10 and Vimentin (8). The sarcomatoid change in RCC can be seen in any subtypes $(9,10)$. About 30 cases of sarcomatoid RCC with heterologous elements has been described in literature (11). The sarcomatoid changes in RCC is the result of dedifferentiation of the parent tumor into high grade malignancy with poor prognosis (12). The previous reports found that $5 \%$ of RCC have sarcomatoid differentiation and it is found most commonly associated with CRCC (9\%) than conventional RCC (8\%) and papillary RCC (3\%) (10). The sarcoma component of RCC generally consists of spindle cell sarcoma areas such as malignant fibrous histiocytoma or fibrosarcoma (8). Presence of sarcomatoid area upgrades the tumor to World Health Organization/ International Society of Urological Pathology (WHO/ISUP) grade 4. The percentage of heterologous area varied between $5 \%$ to $70 \%$ in the whole tumor volume. Although heterologous differentiation in the form of osteosarcoma or rhabdomyosarcoma are seen very rarely $(4,10)$. So far, 11 cases of sarcomatoid chromophobe RCC containing heterologous elements have been reported $(3,12,13)$. In chromophobe RCC, the presence of osteosarcoma in sarcomatoid component is documented in only five cases, two of which also showed chondrosarcomatous differentiation (7). Toshiki Hyodo et al. reported a case of chromophobe RCC with sarcomatoid differentiation that had multiple heterologous components including chondrosarcoma, osteosarcoma and a lipomatous area (13). The CRCC cases with sarcomatoid differentiation in the literature have shown distant organ metastases such as to the bone, liver, lung and lymph nodes. CRCC is mostly seen in stage T1 and T2; only $10 \%$ cases show extracapsular extension (1). In the present case, CRCC showed sarcomatoid differentiation having heterologous component with perinephric fat involvement, perineural invasion and metastasis to periaortic lymph nodes, supporting the presence of a tumor progression pathway from chromophobe to sarcomatoid RCC. Rezakhaniha et al. found that CXCR3 is highly expressed in renal cancer cells as compared to the normal surrounding renal parenchyma. They also found that CXCR3 is well correlated with tumor metastasis and stages and CXCR2 is associated with high grade tumor, advance stages and tumor metastasis. And they concluded that overall overexpression of both chemokines are associated with poor prognosis (14). Presence of only sarcomatoid cells in tumor are placed in the 'unclassified' category in the WHO classification. The closest differential of CRCC is renal oncocytoma and clear cell RCC with granular cytoplasm. Oncocytoma and CRCC both arise from intercalated cells and are usually confined to the kidney and show tan color. Central stellate scar can be seen in both oncocytoma (33\%) and CRCC (15\%). However, histomorphology of Clear cell RCC, oncocytoma and CRCC are different. In the present case, tumor cells are immunopositive for CK7 and immunonegative for CD10 and Vimentin and this ruled out the possibility of conventional clear cell RCC and oncocytoma.

\section{Conclusion}

CRCC containing osteosarcoma component, is very rare but its presence increases the aggressiveness and risk of metastasis. The correlation between the presence of heterologous elements and prognosis is unknown because of the rarity of this phenomenon. It is important to recognize this variant by extensive sampling.

\section{Acknowledgements}

The authors would like to thank all those who helped them writing this article.

\section{Conflict of Interest}

The authors declared that there is no conflict of interest regarding the publication of this article.

\section{References}

1. Cohen Moch H, Humphrey PA, Ulbright TM, Reuter VE eds. WHO Classification of Tumours of the Urinary 
System and Male Genital Organs. 4th edn. Lyon: IARC, 2016. [DOI:10.1016/j.eururo.2016.02.029] [PMID]

2. Thoenes W, Storkel S and Rumpelt HJ. Human chromophobe cell renal carcinoma. Virchows Arch B Cell Pathol Incl Mol Pathol. 1985;48:207-17. [DOI:10.1007/BF02890129] [PMID]

3. Quiroga-Garza G, Khurana $\mathrm{H}$, Shen $\mathrm{S}$, et al.. Sarcomatoid chromophobe renal cell carcinoma with heterologous sarcomatoid elements. A case report and review of the literature. Arch Pathol Lab Med. 009 Nov;133(11):1857-60.

4. Steffens S, Janssen M, Roos FC et al. . The Fuhrman grading system has no prognostic value in patients with nonsarcomatoid chromophobe renal cell carcinoma. Hum Pathol. 2014 Dec;45(12):2411-6. [DOI:10.1016/j.humpath.2014.08.002] [PMID]

5. Paner GP, Amin MB, Alvarado-Cabrero I, et al. . A novel tumor grading scheme for chromophobe renal cell carcinoma. Prognostic utility and comparison with Fuhrman nuclear grade. Am J Surg Pathol. 2010 Sep;34(9):1233-40. [DOI:10.1097/PAS.0b013e3181e96f2a] [PMID]

6. Cheville JC, Lohse CM, Zincke H et al. . Sarcomatoid renal cell carcinoma: An examination of underlying histologic subtype and an analysis of associations with patient outcome. Am J Surg Pathol. 2004;28:435-41. [DOI:10.1097/00000478-200404000-00002] [PMID]

7. De Peralta-Venturina M, Moch H, Amin M, et al.. Sarcomatoid differentiation in renal cell carcinoma: a study of 101 cases. Am J Surg Pathol. 2001;25:275-84. [DOI:10.1097/00000478-200103000-00001] [PMID]

8. Li YF, Cha TL, Jin JS et al.. Chromophobe renal cell carcinoma with osteosarcoma differentiation: Case report and literature review. Urol Int. 2010;85(4):470-4. [DOI:10.1159/000319420] [PMID]

9. Viswanathan S, Desai SB, Prabhu SR, et al.. Squamous differentiation in a sarcomatoid chromophobe renal cell carcinoma: an unusual case report with review of the literature. Arch Pathol Lab Med. 2008 Oct;132(10):1672-4.

10. Husain A, Eigl BJ, Trpkov K. Composite chromophobe renal cell carcinoma with sarcomatoid differentiation containing osteosarcoma, chondrosarcoma, squamous metaplasia and associated collecting duct carcinoma: a case report. Anal Quant Cytopathol Histpathol. 2014;36:235-40.

11. Aird JJ, Nic an Riogh AU, Fleming S, Hislop RG, Sweeney P, Mayer N. Papillary renal cell carcinoma with osteosarcomatous heterologous differentiation: A case report with molecular genetic analysis and review of the literature. Int J Surg Pathol. 2017 Dec;25(8):745-750. [DOI:10.1177/1066896917716772] [PMID]

12. Cserni G, Kovács BR, Tarján M, et al.. Sarcomatoid renal cell carcinoma with foci of chromophobe carcinoma. Pathol Oncol Res. 2002;8:142-4. [DOI:10.1007/BF03033725] [PMID]

13. Toshiki Hyodo, Maki Kanzawa, Shigeo Hara, et al.. Chromophobe renal cell carcinoma with sarcomatoid differentiation containing various heterologous components. Pathology International. 2018;68(9):524-9. [DOI:10.1111/pin.12704] [PMID]

14. Bijan Rezakhaniha, Banafshe Dormanesh, Hamid Pirasteh et al.. Immunohistochemical Distinction of Metastases of Renal Cell Carcinoma with Molecular Analysis of Overexpression of the Chemokines CXCR2 and CXCR3 as Independent Positive Prognostic Factors for the Tumorigenesis. IUBMB life. 2016; 68(8): 62933. [DOI:10.1002/iub.1520] [PMID]

\section{How to Cite This Article}

Bharti, S., Ram Choudhary, G., Jyotsna Bharti, N., Kumar, G., Abhay Elhence, P., BS, A. Sarcomatoid Chromophobe Renal Cell Carcinoma with Heterologous Component. Iranian Journal of Pathology, 2020; 15(1): 56-60. doi: 10.30699/ijp.2019.109242.2147 